\title{
O poder das palavras: relações de alteridade no seio do povo brasileiro, entre branquitude e negritude
}

\section{The power of the words: relations of alterity within the Brazilian people,} between whiteness and negritude

Liz Feré 1

Université Paris VIII, Centre d'Études sur les Médias, les Technologies et l'Internalisation. Paris, França.

Doutora em Ciências da Informação e da VIII. Pertence e professora na Universidade París d'Études sur les Médias, les Technologies l'Internalisation (CEMTI), unidade de pesquisa da escola doutoral da mesma universidade. E membro da Associação de Discursos da América Latina (ADAL).

https: Hord org $0000-0001-9210-4568$

E-mail: info@lizfere.com
RESUMO: 0 presente artigo trata da maneira como, na sociedade brasileira, as relações de alteridades se traduzem no discurso cotidiano atual, no que diz respeito às relações raciais. Tais discursos revelam, além da existência de uma base teórica racista profundamente enraizada, uma falta de consciência da realidade concreta da discriminação racial no Brasil e a persistência da ideia segundo a qual a sociedade brasileira não é racista. A análise qualitativa desenvolvida parte da visão de brasileiros afrodescendentes, estudada através de um questionário googledoc, tratado pelo Programa Iramuteq, $e$ fundamentada nas teorias do círculo de Bakhtin em diálogo com Bourdieu. 0 estudo aponta de que modo a linguagem influencia as relações pessoais, especialmente como a palavra e suas valorações potencializam as tensões vividas entre grupos cada vez mais antagônicos.

Palavras-chave: Negritude; Alteridade; Relações de poder; Discriminação; Palavra.

ABSTRACT: The present article deals with the way in which, in Brazilian society, the relations of alterities are translated in the current discourse of the present day, with respect to race relations. These discourses reveal not only the existence of a deeply rooted theoretical base, but also a lack of awareness of the concrete reality of racial discrimination in Brazil, and the persistence of the idea that Brazilian society is not racist. The qualitative analysis developed, part of the vision of Brazilian Afrodescendants, studied through a questionnaire googledoc, treated by the Iramuteq Program and based on the theories of Bakhtin's circle, in dialogue with Bourdieu. The study points out in what way language influences personal relationships, especially how the word and its values potentiate the tensions experienced between groups increasingly antagonistic.

Keywords: Blackness; Otherness; Power relations; Discrimination; Word. 


\section{Considerações iniciais}

O Brom

Brasil é o segundo país em população negra no mundo, mas também um dos que possui as mais rígidas formas de hierarquias sociais. Em tal contexto, o mais difícil é distinguir as desigualdades econômicas e sociais daquelas ligadas à cor da pele.

A condição de vulnerabilidade socioeconômica, o descaso e o abandono a que foram relegados os negros após a abolição da escravatura, em 1888, persistem atualmente e ganham força no atual cenário de crise. Uma das provas de que essa realidade perdura é dada pelo fato de que continuamos a reproduzir, na linguagem e no comportamento, os estigmas da época da escravatura.

A nação brasileira é uma das campeãs na lamentável classificação mundial das desigualdades sociais. E os que mais sofrem com esse desequilíbrio são os negros, que correspondem a pelo menos $54 \%$ da população, posto que esta é a percentagem dos brasileiros e brasileiras que se autodeclaram negros (ou pardos), segundo o censo do IBGE de 2010.

Convém no entanto ressaltar que, no contexto brasileiro atual, há uma evolução no debate público, a qual enriquece as questões raciais. Esse fenômeno inclui novas mídias temáticas da negritude, bem como uma tomada de consciência da valorização do negro, que busca usufruir do que lhe é de direito, a dignidade. Contudo, devemos levar em conta aspectos que estão enraizados na sociedade brasileira e que têm um grande peso no processo de exclusão. São partes de um conjunto configurado a vários níveis, tais como sociais, culturais e econômicos. Esses elementos podem ser dissociados, mas são fortemente interconectados.

O objetivo deste estudo é propor uma reflexão sobre como a linguagem reforça discursos estigmatizantes contra pessoas negras no Brasil. Para tanto, são analisados enunciados resultantes de questionários e entre- vistas a afrodescendentes brasileiros, considerando o levantamento de palavras e suas associações no discurso, bem como valorações enquanto signo ideológico. Desse modo, é considerado o sentido construído no discurso, o contexto específico em que as palavras são utilizadas, e as relações de poder na linguagem. Isso se deve ao fato de muitos discursos tidos como sutis, normais, ou até aparentemente elogiosos serem, na maioria das vezes, carregados de estigmas do ponto de vista daqueles que os recebem.

Essa problemática central que levou ao desenvolvimento deste estudo está atrelada à questão de a linguagem ser constitutiva da construção e desconstrução identitária dos sujeitos afrodescendentes brasileiros. Nesse contexto, seria possível pensar na relação de alteridade do povo brasileiro entre branquitude e negritude?

Podemos dizer que a construção e reprodução de estereótipos discriminatórios resultam de um processo de objetivação, no qual a pessoa, quanto mais sua pele for escura, mais será estigmatizada e mais será desprovida de sua identidade individual, aniquilada pelo estereótipo generalizante associado à cor da pele. Em tal contexto, em que uma minoria branca dominante impõe suas regras a uma maioria negra, esses dominantes ocupam um espaço confortável e quase nunca questionável no topo da hierarquia social. São eles que determinam os princípios da hierarquização, conservam suas ideologias, realizam ações para legitimar sua dominação e, assim, guardar as rédeas da construção do mundo social.

A abordagem do objeto racismo se faz aqui a partir da formulação de hipóteses sobre identidade, diferenças e suas interações no domínio discursivo e simbólico. Seria impossível dissociar a noção de discriminação da de estereótipo, que significa somente as imagens que se integram em nossa mente e que servem para mediar nossa relação com o real. Trata-se, nesse sentido, de representações culturais preexistentes que filtram a 
realidade. Essas "imagens" ou impressões que criamos ou assimilamos, sejam verdadeiras ou não, fazem parte do nosso imaginário social.

Cada indivíduo pertence a um grupo, a grupos de referência, sejam reais, ideais ou imaginários. O pertencimento a diferentes grupos varia em função de critérios diversos: idade, sexo, classe social, profissão, cor da pele, afinidades, questões culturais, religiosas, e ideológicas, bem como, centro de interesses. Diante da complexa questão da identidade cultural, seguimos algumas reflexões no que diz respeito aos mecanismos de sua construção e dos aspectos imaginários que a constituem. A consciência identitária começa a partir do momento em que reconhecemos no outro uma diferença.

No âmbito da rígida hierarquização da sociedade, na qual a democracia racial não passa de quimera, as crianças são as grandes vítimas dessa engrenagem de descaso e discriminação. Do ponto de vista do sociólogo brasileiro Jessé Souza (2016), as crianças, quando ingressam na escola, já chegam como vencedoras ou perdedoras. Em tais circunstâncias a escola ajuda a legitimar a ilusão do "mérito caído do céu" de alguns e o "estigma" de outros. Seguindo a lógica bourdieusiana aplicada ao caso brasileiro, é possível entender que é principalmente no sistema escolar que são fortalecidas as barreiras que separam e distinguem as classes sociais, o que mais tarde será acentuado no competitivo mundo do mercado de trabalho.

Esse dispositivo de controle social está enraizado na sociedade brasileira, inclusive no meio dos dominados. Isso é facilmente compreensível se temos consciência de que o engodo da "meritocracia", quando bem apresentado, soa como legítimo. E é bem verdade que no Brasil existe uma construção social do "privilégio" tão bem orquestrada que muitos acabam aceitando a ilusão de que existem "naturalmente" seres "muito inteligentes", que merecem salários exorbitantes, e os "preguiçosos" que têm o que "merecem", visto que não querem trabalhar e "dar duro", os chamados "vagabundos".
E é nesse cenário conflituoso de alteridade que os brasileiros se vêem fragmentados entre "nós" e "eles", desde a mais tenra infância.

\section{0 poder das palavras entre "nós" e "eles"}

A convivência entre os sujeitos é carregada de conflitos, pois se dá sob uma forte relação de dominação que, segundo Bourdieu (1982), diz respeito à relação entre indivíduos que ocupam diferentes posições no espaço social: os dominantes e os dominados.

Essa hierarquia é fundamentada através da linguagem, visto que a palavra é um fenômeno ideológico por natureza, na medida em que carrega um peso de valores culturais que evidenciam as diferenças de opiniões "e as contradições da sociedade, tornando-se um palco de conflitos" (BAKHTIN, 2017, p. 282). São palavras e expressões repetidas cotidianamente que carregam o peso de construção ou destruição do indivíduo na qualidade de ser social.

A enunciação está intimamente ligada às condições da comunicação, que, por sua vez, estão relacionadas às estruturas sociais, de natureza social (portanto ideológica); a enunciação não existe fora de um contexto social. "A palavra é o campo onde se confrontam os valores sociais; os conflitos da língua refletem os conflitos de classe no interior mesmo da estrutura: baseada entre classe social e comunidade semiótica"1 (BAKHTIN, 2017, p. 233).

A interação verbal, indissociável das outras formas de interação, acarreta conflitos, relações de dominação e de resistência, aceitação, submissão ou resistência à hierarquia, utilização da língua pela classe dominante para reforçar seu poder. De acordo com o pensamento bakhtiniano:

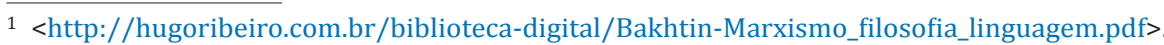


Na realidade, não são palavras o que pronunciamos ou escutamos, mas verdades ou mentiras, coisas boas ou más, importantes ou triviais, agradáveis ou desagradáveis etc. A palavra está sempre carregada de um conteúdo ou de um sentido ideológico ou vivencial. É assim que compreendemos as palavras e somente reagimos àquelas que despertam em nós ressonâncias ideológicas ou concernentes à vida (BAKHTIN, 2003, p. 95).

O filósofo russo interessou-se pela maneira como é produzida a significação das palavras e pelo funcionamento dos discursos da vida cotidiana, aqueles que se relacionam diretamente com a situação em que são produzidos, nos quais se identifica mais facilmente a natureza social da linguagem. A linguagem é uma prática social cotidiana que envolve a experiência do relacionamento entre sujeitos, e tal experiência é parte integrante do sentido do dizer. Dessa forma, a língua é entendida não como um sistema abstrato de formas linguísticas à parte da atividade do locutor, mas como um "processo de evolução ininterrupto, constituído pelo fenômeno social da interação verbal, realizada através da enunciação, que é a sua verdadeira substância" (BAKHTIN, 2017, p. 127).

Tais reflexões são importantes para abordar o universo vivido pelos negros no Brasil, considerando, nessa perspectiva, o valor da palavra e como ela constitui, alimenta, constrói e desconstrói a realidade. Segundo Bakhtin:

Toda palavra comporta duas faces. Ela é determinada tanto pelo fato de que procede de alguém, como pelo fato de que se dirige para alguém. Ela constitui justamente o produto da interação do locutor e do ouvinte. Toda palavra serve de expressão em relação ao outro (BAKHTIN, 2017, p. 113).

Para o autor, toda enunciação é dialógica sobretudo por que é interposta por outros discursos. No caso deste estudo, a constituição heterogênea pode ser observada em entrevistas, realizadas entre maio de 2016 e fevereiro de 2018, que constituem parte do objeto de reflexão do presente artigo. Nos discursos relatados pelos entrevistados, é possível perceber, por um lado, as múltiplas vozes que atravessam os discursos e, por outro, o funcionamento da palavra como um vínculo, um território comum entre "eu" e os "outros" quando relacionado à coletividade.

Quando alguém formula enunciados, como "só poderia ser negro(a)" ou "trabalho de preto", fica claro que não se trata unicamente da descrição de elementos da realidade, mas sim da associação ao imaginário coletivo, que o valora como uma afirmação pejorativa. No caso do primeiro enunciado, "só poderia ser negro(a)", há um tom depreciativo, impregnado de vozes sociais, reconhecidas pela coletividade, que justifica um suposto erro do outro pela cor da pele, negra, desse outro. Esses discursos com apreciação negativa dialogam, muitas vezes, com outros irônico-sarcásticos, estabelecendo relações de sentidos entre os diferentes enunciados.

O segundo enunciado, "trabalho de preto", também carrega uma entonação insultuosa, altiva. Ao fazer alusão a uma tarefa que tenha sido mal realizada por pessoas negras, entra em contraste com a afirmação "trabalho de branco", designando a suposta capacidade dos brancos de realizar um trabalho, considerado, bem feito. Esses enunciados preconceituosos, representantes de um conjunto maior, são impregnados de lembranças, ecos e referências de outras vozes discursivas que, ao atravessarem o enunciado, fazem emergir diferentes efeitos de sentidos.

\section{Vozes da discriminação em contexto}

Dentre as diferentes vozes que atravessam os enunciados, e com eles estabelecem relações voltadas para a intolerância ao(à) negro(a), estão aquelas que dialogam com discursos que contextualizam históricosocialmente o racismo, as relações de dominação, discriminação e abuso do poder. 
Quanto as vozes que contextualizam o racismo, tomamos a escravidão como um modo totalitário de dominação e exploração de indivíduos por outros, questão fortemente marcada pela alteridade. Já no século V, o Papa Nicolau V (1454) autorizou o comércio de escravos africanos. A escravização do povo negro seria, conforme certas "teorias" da época, a execução de uma "profecia" bíblica, segundo a qual os negros, descendentes de Caim, filho amaldiçoado de Noé, estariam condenados à escravidão perpétua.

No final do século $\mathrm{XV}$, foram criados o conceito de raça e a ideia de "superioridade racial" pelos "sábios" do período da expansão europeia. Os propósitos eram apresentados como "científicos".

Nesse cenário, é possível perceber que as representações discriminatórias têm suas origens em tais crenças, reforçadas pela influência e pelo poder político dominante no seio da igreja católica. Os negros eram considerados como "malditos" e "desalmados" e, por isso, situados fora da condição humana. Poderiam assim ser tratados como animais fadados à escravidão e, sem maiores consequências, sofrer maus tratos e violência.

No final do século XIX, desenvolvem-se diversas correntes teóricas racistas, influenciadas pelas ideias evolucionistas e pseudo progressistas. Um dos mais importantes teóricos, considerado pai do racismo alemão, foi o Conde Arthur de Gobineu, autor do Ensaio sobre a desigualdade das raças humanas. A teoria de Gobineu serviu de base a outras correntes do racismo dito "científico". Outro grande teórico do pensamento racista foi o italiano Cesare Lombroso (ironia da história, Lombroso era de família judia), responsável pelo fundamento da "ciência racista", no campo da antropologia criminal. Em suas obras, ele repertoria as particularidades físicas das pessoas supostamente predispostas ao crime pela hereditariedade, a partir do "estudo" de crânios de assassinos guilhotinados, de soldados delinquentes (Lombroso foi médico militar) e de fotos de condenados e seus biotipos (cf. TAGUIEFF, 2013).
Segundo Claude Lévy-Strauss (1976, p. 204), as distinções entre grupos humanos só podem ter validade em termos culturais. De fato, é pela cultura que os grupos humanos ou sociedades se diferenciam, e não por critérios biológicos. Mas alguns autores misturaram os registros biológico e cultural, desenvolvendo uma nova ideologia, um racismo que se apresenta como a teoria "científica" da "hierarquia das raças". Uma tal categorização teve como consequência a hierarquização dos grupos humanos e conduziu à propagação da noção de "raças inferiores", o que serviu de argumento para legitimar as ações dominadoras dos colonizadores europeus.

0 racismo é uma consequência bem real dessa teoria fundamentada no pressuposto errôneo da existência de "raças" humanas e na escolha ideológica de hierarquizá-las. As especificidades psicológicas dos indivíduos têm pouca importância no processo que estrutura a noção de racismo. Este traduz-se em expressão simbólica e cultural de uma sociedade organizada e historicamente hierarquizada em torno da dominação exercida por um grupo social sobre outro (cf. TAGUIEFF, 2013).

No Brasil, a escravidão se deu entre os séculos XVI e XIX, quando homens e mulheres de vários lugares do continente africano foram violentamente capturados e obrigados ao trabalho forçado e à exploração. A profusão de africanos no Brasil foi tanta que os escravizados chegaram a constituir mais de $75 \%$ da população em várias regiões, como é o caso do Recôncavo Baiano.

As desigualdades, injustiças e humilhações não diminuíram com o fim da escravidão, em maio de 1888 (FAUSTO, 2007). Os europeus que imigraram ao país sempre foram avantajados em relação aos ex-escravos, para os quais restavam os trabalhos mais precários e com rendas inferiores, tais como engraxates, varredores, quitandeiras etc.

A conjuntura brasileira mudou e evoluiu muito de lá para cá, contudo a cor da pele dos brasileiros está frequentemente no coração das relações sociais, por vezes de maneira sutil, outras vezes de forma dissimulada, 
direta ou agressiva. Essa relação de dominação, ainda hoje, está presente na sociedade brasileira.

No que diz respeito às relações de dominação, discriminação e abuso do poder, entende-se por dominação de um grupo ou de uma classe social sobre outro(a), uma realidade inserida no cotidiano por meio de sistemas intrínsecos de práticas sociais e sócio-cognitivas, quer dizer as práticas que constituem os conhecimentos adquiridos durante as interações sociais. Os diversos campos semânticos articulados nos discursos racistas possuem características duplas de caráter muito geral (como nas relações "nós" versus "os outros"; "ameaçador" versus "ameaçado") e organizam o universo semântico racista. As categorias semânticas são "invisíveis" na medida em que estruturam as condições gerais da experiência representada nos discursos, o quadro espaço-temporal e os modos elementares de ação. Da interação de todos esses processos é que nasce a oposição entre "nós" e "os outros", entre "nós" e "eles".

O conceito de discriminação, nesse contexto, designa os comportamentos estigmatizantes de um grupo de indivíduos com relação a outros, em razão de seu pertencimento a um grupo social dado. A discriminação pode ser indireta e discreta, quando há a aplicação de uma regra na qual a neutralidade é aparentemente indiscutível, conduzindo à desvantagem das pessoas que pertencem a um grupo determinado, no caso de nosso estudo, as pessoas negras. Um exemplo comum desse tipo de discriminação são situações como: um negro/mestiço chega para uma determinada entrevista de emprego e o responsável afirma que a vaga já foi preenchida. E normalmente por alguém, de igual ou menor competência, mas de pele branca.

Não há como abordar a questão discriminatória sem mencionar o preconceito, que nada mais é, de acordo com a psicologia social, que um julgamento negativo em relação a alguém ou a um grupo, baseado na atribuição infundada de certas características. O preconceito é uma forma de relação intergrupal organizada em torno das relações de poder entre grupos, produzindo representações ideológicas que justificam a expressão de atitudes negativas, bem como comportamentos discriminatórios em relação a outros grupos (PEREIRA; TORRES; ALMEIDA, 2003).

Desde o século XIX, lembra Eni Orlandi (2008), a elite aristocrática brasileira vinda de Portugal usava a linguagem dos mestres, tais como advogados e notários, como meios de exclusão social. E essa realidade é ainda presente, nas esferas políticas, acadêmicas e outros cargos ocupados nos meios mais favorecidos da sociedade brasileira. Desde a época colonial, o Brasil mantém códigos arcaicos de dominação. Também há heranças aristocráticas que ainda estão presentes nos espaços democráticos, como as redes sociais ou uma ágora.

Para Bourdieu (2002), o poder simbólico que os dominantes exercem sobre os dominados tem a capacidade de estabelecer o que é considerado como dado por meio da elocução, de ver e fazer crer, de confirmar ou modificar a visão do mundo e, assim sendo, a ação sobre o mundo.

Se as trocas linguísticas são relações de comunicação, elas não se reduzem de forma alguma a essa função. Isolar a linguagem de suas condições sociais de produção é ignorar que a resposta à questão da eficácia simbólica da comunicação não está na linguagem em si, mas no mundo social que a produziu. Logo, as relações de comunicação são relações de poder fundadas em um arbítrio, em relações de violência simbólica socialmente instituídas (BOURDIEU, 2008).

Nesse contexto, Bourdieu considera que a autoridade seria o que concede ao locutor a possibilidade de se expressar outorgada pelas instituições sociais. Dessa forma, a autoridade que confere a palavra viria de uma força exterior à estrutura da linguagem. Essa autoridade - vinda do locutor associado à instituição que, na visão do autor, o autoriza a expressar- 
se - que, amplificada à estrutura linguística do discurso, propicia a eficiência dos símbolos contidos na linguagem.

Nesse ponto é que as ideias de Bourdieu vão encontrar as do filósofo russo Bakhtin, quando diz que a compreensão dos signos dá-se em ligação com a situação, o contexto em que ele toma forma, e esse contexto, essa situação é sempre social. O signo ideológico na constituição do sujeito, afirma o filósofo, parte do exterior para o interior, ou seja, do "social para o individual", e a palavra nada mais é do que produto de interação viva das forças sociais (BAKHTIN, 2017).

Abordando uma realidade especificamente brasileira, imersa na hierarquia social, Roberto Damatta (c.f. 1997, p. 179-248) ressalta um aspecto relevante da sociedade presente no discurso dominante e sobretudo no cotidiano dos dominados: algumas expressões que colocam certos indivíduos "nos seus lugares" dentro de uma relação de poder e dominação. Trata-se de enunciados do tipo "Você sabe com quem está falando?", usadas frequentemente para marcar as relação de poder e reforçar a posição do dominante.

Nessa relação de dominação, a imagem dos negros está condicionada pelo lugar-comum e pelos estereótipos e é deformada por aqueles que têm ou consideram ter a pele mais clara que a do "estigmatizado". O estigma contra negros é construído na sociedade brasileira de forma profunda e está presente em diferentes relações da vida cotidiana. Essa reflexão sobre o estigma pode ser ampliada a partir da visão de Goffmann:

Construímos uma teoria do estigma; uma ideologia para explicar a sua inferioridade e dar conta do perigo que ela representa, racionalizando algumas vezes uma animosidade baseada em outras diferenças, tais como as de classe social. Utilizamos termos específicos de estigma como aleijado, bastardo, retardado, em nosso discurso diário como fonte de metáfora e representação, de maneira característica, sem pensar no seu significado original (GOFFMAN, 1981, p. 8-9).
Atribuir estigmas está associado aos pré-julgamentos e aos estereótipos tão bem construídos que se inserem no seio da sociedade como algo tangível e até "justificável" por determinados grupos de pessoas. $\mathrm{O}$ uso de alguns termos ${ }^{2}$ para se referirem a negros(as), tais como "sujo", "violento", "encardido", evidencia a despreocupação daqueles que os proferem para com os estigmatizados. Isso por que a "branquitude", no caso a brasileira (os poucos que fazem parte dela), ocupa um espaço privilegiado e dificilmente é levada a responsabilizar-se por esses dizeres insultantes, visto que durante séculos de história, na construção brasileira de senhores e escravos, os discursos insultantes foram sendo incluídos como corriqueiros. Dentro dessa conjuntura, os afrodescendentes brasileiros são confrontados, desde crianças, a conviver com o estigma da inferioridade, atribuído por uma minoria.

\section{Branquitude e negritude no Brasil}

No imaginário coletivo, a conotação pejorativa relacionada a palavra "preto" (pecado, mal) se constrói em oposição a "branco" (pureza, virgindade). À partir de 1650, com o tratado escravagista, a palavra "preto" se confunde com "negro". Desde o século XIII, o campo semântico da palavra "branco" se estabelece em correlação com o tráfico de humanos e posteriormente ao termo "negro". E ganhou uma dimensão social (a mais baixa da escala hierárquica), política e biológica com o desenvolvimento das plantações nas Américas (cf. TAGUIEFF, 2013, p. 218).

A valorização dos brancos é um fato mundial, com ênfase em países colonizados por europeus que instituíram a escravidão. No entanto, em meados de 1990, a branquitude começou a ser objeto de estudos críticos, sendo os pesquisadores estadunidenses os precursores dessa nova

2 Palavras extraídas das respostas dos entrevistados, via software Iramuteq. 
perspectiva abordada nas ciências sociais, batizada critical whiteness studies. Segundo a pesquisadora Lia Schucman (2012, p. 27), os estudos revelam que os olhares estão se deslocando dos "outros", racializados, e se dirigem para o ponto central, os brancos, pois são eles os responsáveis pela produção e manutenção da ideia de "raça", no campo sociológico, na tentativa de legitimar práticas cotidianas discriminatórias que inferiorizam os demais grupos humanos.

O racismo, para Foucault (1992), é uma forma de dominação que se solidificou fundada em uma ideia "científica" da luta entre raças, o que desencadeou um racismo "biológico-social" com base na premissa que reconhece uma superioridade do branco-europeu. Essa dita "superioridade" incluiria o físico (estético), moral e sobretudo intelectual, benefícios atribuídos aos brancos no que diz respeito às "verdades" e normas (cf. SCHUCMANN, 2012, p. 35).

No que se refere a cor da pele, mesmo se pouco significativa em si, é importante, uma vez que constitui um significante, uma materialidade sobre a qual se inscrevem sócio-históricamente determinados discursos. Hall (2013), ao mesmo tempo que recusa uma concepção essencialista, afirma que a noção de raça, mesmo se cientificamente falsa tem consequências reais, "já que podemos constatar seus efeitos [...], ver a discriminação racial que funciona nas instituições, e assim por diante", estabelecendo hierarquias na organização social.

Apesar do avanço dos movimentos em prol da negritude, que ocupam cada vez mais o espaço público mundial e brasileiro, a branquitude ainda é tomada, vista e aceita como sendo padrão de "normalidade". O processo de construção e reconstrução identitária toma o branco como referência a outros grupos, os quais são colocados à margem da sociedade.

Nessa perspectiva, um aspecto do racismo específico à sociedade brasileira é a ideologia do "branqueamento" marcado por uma estrutura hierárquica de desigualdades sociais no que diz respeito aos negros, mestiços e também aos índios. Em tal estrutura, uma minoria branca é socializada e constituída envolta num sentimento de "supremacia" racial tão fortemente inserido na sociedade brasileira quanto a teoria racista, ainda presente, segundo a ideia de que os negros seriam inferiores moralmente. Para a pesquisadora norte-americana Frankenburg, a branquitude é "um lugar estrutural de onde o sujeito branco vê aos outros e a si mesmo; uma posição de poder não nomeada, vivenciada em uma geografia social de raça como um lugar confortável e do qual se pode atribuir ao outro aquilo que não atribui a si mesmo" (SOVIK, 2009, p. 19). Embora olhares exteriores vejam o Brasil como sendo um país cordial, hospitaleiro e miscigenado, percebe-se que, em realidade, os dominantes brancos têm dificuldades de convivência, não com estrangeiros, mas com seus próprios compatriotas negros, sobretudo os de baixa renda. As contradições nos discursos revelam a face escondida do racismo à brasileira que consolida uma forma de inferiorização dessa população não branca. Nessa abordagem sobre os brancos brasileiros, a questão das desigualdades entre classes é inserida como sendo consequência da escravidão. Essa estrutura é mantida como critério de estética social (SOVIK, 2009, p. 22).

No Brasil, a branquitude é também uma questão de imagem, de representação de paradigmas idealizados em todas as camadas da sociedade brasileira. Naturalmente, um dos seus principais campos de observação são, dentre outros, os meios de comunicação de massa, novelas, propagandas e redes sociais. De acordo com a ideia de Souza (1983), a branquitude foi construída e perdura até hoje, da seguinte forma:

(...) A brancura transcende o branco. Eles - indivíduo, povo, nação ou estado branco - podem "enegrecer-se". Ela, a brancura permanece branca. Nada pode macular esta brancura que, à ferro e fogo, cravou-se na consciência negra como sinônimo de pureza artística; nobreza; estética; 
majestade moral; sabedoria científica etc. 0 belo, o bom, o justo e o verdadeiro são brancos. 0 branco é, foi e continua sendo a manifestação do espírito, da ideia, da razão. 0 branco, a brancura são os únicos artífices e legítimos herdeiros do progresso e desenvolvimento do homem (SOUZA, 1983, p. 5).

Através dessa estrutura de dominação, que atravessa os séculos, Souza refere-se, assim, à identidade negra que foi e continua sendo massacrada e acrescenta que a melhor maneira de exercer autonomia é deter um discurso sobre si mesmo e concreto na realidade (cf. SOUZA, 1983, p. 17-18).

Quanto ao movimento da negritude, ele veio a fim de lutar pelo renascimento, bem como pela valorização do negro e surgiu nas primeiras décadas do século $\mathrm{XX}$, entre as duas guerras mundiais. Esse movimento cultural, chamado então de "negritude", foi conduzido por protagonistas negros e mestiços. Tais manifestações culturais e políticas tinham como objetivo divulgar e enaltecer as raízes africanas no mundo todo e, sobretudo, em três países das Américas: Estados Unidos, Cuba e Haiti (LOPES, 2005; MUNANGA,1990), mas também nas Antilhas francesas e na África.

O termo negritude, segundo a visão de Lopes, designa um:

(...) neologismo surgido na língua francesa na década de 1930, para significar a circunstância de se pertencer a grandes coletividades africanas e afro-descendentes; a consciência de pertencer a essa coletividade e a atitude de reivindicar-se como tal; a estética projetada pelos artistas e intelectuais negros no continente de origem e na diáspora (LOPES, 2005, p. 472).

O movimento da negritude, idealizado por Aimé Césaire, concentrou suas estratégias para enfraquecer um dos seus pontos mais frágeis e de maior dominação, a linguagem. A negritude, em sua base, foi literária e cultural. Césaire considerava a negritude como forma de introduzir a si mesmo a consciência de ser negro, de sua identidade, cultura e sobretudo sua história. Sartre foi um dos principais intelectuais em prol da negritude: "A unidade final, que aproximará todos os oprimidos no mesmo combate, deve ser precedida nas colônias, por isso que eu chamaria momento da separação ou da negatividade: este racismo anti-racista é o único caminho capaz de levar à abolição das diferenças de raça" (SARTRE, 1960, p. 94).

As relações de alteridade vividas pelos afro-brasileiros e seus conterrâneos brancos é marcada por fortes tensões. Sobre essa questão, Munanga considera que:

Poder-se-ia reter como traço fundamental próprio a todos os negros (pouco importa a classe social) a situação de excluídos em que se encontram a nível nacional. Isto é, a identidade do negro se inscreve no real sob forma de exclusão. Ser negro é ser excluído. Por isso, sem minimizar os outros fatores, persistimos em afirmar que a identidade afro-brasileira mais abrangente seria a identidade política de um segmento importante da população brasileira excluída de sua participação política e econômica (MUNANGA, 1990).

O mito da "democracia racial" foi nefasto no Brasil, ele foi teorizado, em 1933, pelo sociólogo Gilberto Freyre e em seguida por outros autores, e só contribuiu para deslegitimar a voz dos negros quando denunciavam as dificuldades que enfrentavam. Freyre popularizou a ideia de que a escravidão no Brasil teria assumido formas atenuadas, se comparada com a estadunidense. Com a difusão do mito de que o Brasil estaria livre do racismo devido à harmonia e à fusão dos povos, ele contribuiu, assim, para travar o desenvolvimento do debate sobre a realidade do racismo e suas consequências (TELLES, 2003, p. 50).

No entanto as resistências, advindas da comunidade dos quilombos, em prol das raízes do povo negro persistiram, algumas delas conquistaram territórios com direitos à cidadania e políticas públicas. Ainda que muito 
isoladas dos centros urbanos, elas são alvos de grande violência, tanto por parte da polícia, quanto de políticos ou fazendeiros ${ }^{3}$. A partir do início do milênio, surgiram ações afirmativas com recorte racial, tais como o Estatuto da igualdade racial $^{4}$, de 2003, e o sistema das cotas raciais 5 , em 2012, o que propiciou o ingresso de um número maior de negros nas universidades. Houve também uma ênfase no debate público sobre as questões de discriminação por eles vividas cotidianamente.

No entanto, os negros no Brasil, vivem em situação de desvalorização. Segundo dados do IBGE de 2014, ainda que a população negra e parda represente $54 \%$ da população total, somente $17,4 \%$ dos cargos de destaque são ocupados por pessoas desta população. A maior parte está fadada aos serviços mais desvalorizados, sujos e pesados, estando "acostumada" com dificuldades que a parcela da população que desfruta dos privilégios da branquitude, mesmo se pobre, ignora. De acordo com os dados da CPI do Senado, ${ }^{6}$ de 2015, com base no mapa da violência, a cada ano morrem cerca de 23.100 jovens negros com idade entre 15 e 29 anos, uma média de 63 por dia ou 1 a cada 23 minutos.

A partir dessas observações, percebe-se que, apesar de alguns avanços no reconhecimento do espaço do negro brasileiro na sociedade, muito ainda deve ser feito para que sua voz ganhe o destaque merecido, reflexão que pode ser observada, em parte, na próxima seção.

\footnotetext{
3 <https://www.almapreta.com/editorias/realidade/conheca-7-liderancas-politicas-quilombolasassassinadas-em-um-ano-no-brasil >.

4 Institui o Estatuto da Igualdade Racial; altera as Leis nos 7.716, de 5 de janeiro de 1989, 9.029, de 13 de abril de 1995, 7.347, de 24 de julho de 1985, e 10.778, de 24 de novembro de 2003. <http://www. planalto govbr/ccivil_03/ato2007-2010/2010/lei/112288 html> (Vide Decreto no 8.136, de 2013). planã̃e sov.re o ingresso nas universidades federais e nas instituiç̃̃es federais de ensine técnico de nível médio e dá outras providências. <http://wa lei/112711.htm>. lei/112711.htm>.

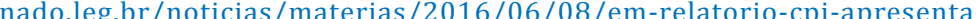
sugestoes-para-acabar-com-genocidio-da-juventude-negra>. Dados de 2015.
}

\section{Análise de relações de alteridade através da percepção dos afrodescendentes}

O presente estudo problematiza a discriminação de pessoas negras no Brasil e visa observar, através de enunciados de brasileiros afrodescendentes, como a linguagem reforça a discriminação racial no país. Para tanto, foram consideradas as respostas de entrevistas com 15 pessoas e de um questionário que permitiu a obtenção de 471 respostas, de vários estados brasileiros. $^{7}$

A análise valeu-se do software de análise estatística Iramuteq ${ }^{8}$ e de uma metodologia qualitativa do conjunto dos relatos. A partir da análise dos resultados, coletados através do software, foi possível identificar uma manifestação retórica articulada a uma série de palavras e expressões que revelam o que os afrodescendentes brasileiros mais escutam no seu cotidiano'.

Dentre os questionamentos elaborados, passemos a observar o que mais teve destaque nas interações: Quais as palavras ou outras formas de expressão utilizadas no Brasil, segundo você, evidenciam o racismo e a discriminação contra pessoas negras ou pardas?

Para tanto, foi observado, no levantamento efetuado, o ponto de vista de locutores negros nas inter-relações com brancos e pardos. A análise em foco considera que as palavras e expressões linguísticas constituem discursos ao mesmo tempo que se associam a outros discursos, que são, como mencionado, de natureza social e não individual. Os efeitos de sentido em uma enunciação, seja escrita ou oral, se constitui na relação entre

7 O questionário faz parte de uma pesquisa maior que está sendo desenvolvida no CEMTI (Paris VIII) 8 O software IRAMUTEQ (Interface de Recherche pour les Analyses Multidimensionnelles de Textes et de Questionnaires) foi desenvolvido por Pierre Ratinaud e Pascal Marchand (2009). Sitio <web: http:// www.iramuteq.org>.

9 Vale salientar que, do total de 471 relatos de afro-brasileiros, 11 pessoas autodeclararam-se brancas, mas mencionam discursos que consideraram racistas contra amigos e sobretudo parentes. 
interlocutores no uso da língua, face às conjunturas sociais de produção do enunciado (cf. ORLANDI, 1996).

As palavras levantadas são consideradas, de acordo com Bakhtin/ Volochinov (2017, p. 281), signos ideológicos. Todo signo é ideológico depende do valor simbólico que lhe é atribuído, tendo em vista o contexto e os parceiros de uma dada interação. Assim, são considerados na produção dos sentidos, dentre outros elementos, o modo como a interação se desenvolve, o seu objetivo, os interlocutores e as posições ocupadas em determinado cenário. $\mathrm{O}$ signo comporta uma polivalência social no que se refere ao seu valor contextual. $O$ fato de diferentes grupos sociais empregarem o mesmo conjunto de elementos linguísticos faz com que as palavras revelem valores ideológicos contrastantes, tendo o seu sentido firmado pelo contexto em que ocorrem. É a situação social imediata a responsável pelo sentido.

Passemos a observar o levantamento de palavras que se referem ao racismo e à discriminação.

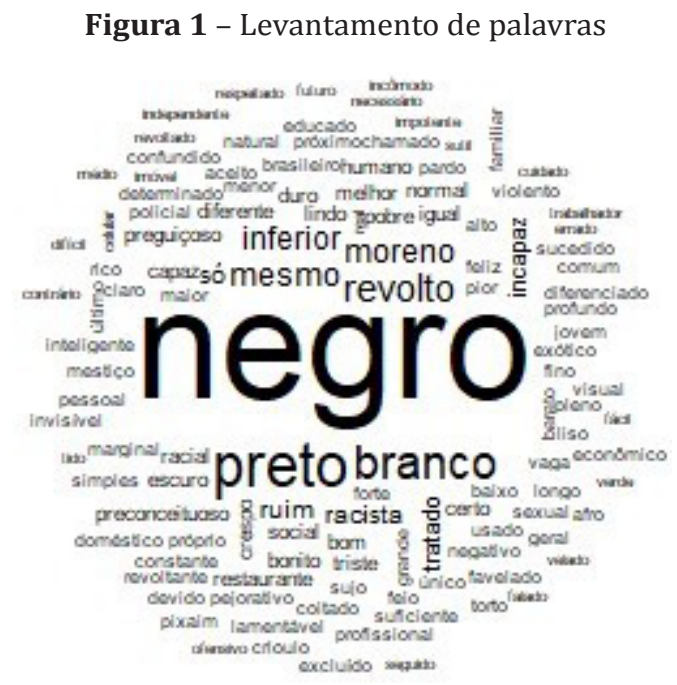

Fonte: Dados IRAMUTEQ 2016-2018
Por meio dessa nuvem de palavras, é possível observar os signos ideológicos em três graus de ocorrência: quanto maior a dimensão tipográfica da palavra mais esta é constante no discurso. As palavras foram identificadas e quantificadas de acordo com a frequência e pelas posições ocupadas no texto. Também são associados ao levantamento signos menos utilizados, mas que são relevantes, devido ao valor assumido nos enunciado.

(1) As palavras evidenciadas em primeiro plano, com maior ocorrência, são negro, preto e branco.

(2) As palavras que estão destacadas em segundo plano são moreno, inferior e revolto. Foram observadas também em relação às palavras levantadas nas ocorrências respostas com expressões "eufemizadas", tais como moreninho(a), escurinho(a), neguinho(a), pretinho(a), passadinho(a) (do ponto), bronzeadinho(a) (demais), beleza (exótica).

(3) Outras palavras figuram na nuvem, em ocorrências variáveis entre (i) incapaz, pejorativo, (ii) preguiçoso, marginal, pobre, violento, mulato, sujo, excluído. Também há signos que fazem alusão ao cabelo crespo: ruim, duro, pixaim etc.

Observando as ocorrências levantadas, podemos perceber, nas palavras correspondentes ao primeiro plano (1), uma questão primordial relativa ao universo da alteridade entre brancos e negros no Brasil. O uso de "negro" ou "preto" em contrapartida a "branco", visto que alguns grupos preferem uma ou outra designação para se referir à população negra, permite perceber a questão do que seria tolerado como designação pelos brancos para referirem-se aos afrodescendentes.

O signo ideológico, conforme o pensamento bakthiniano, é representado pelo viés da relação entre consciência, ideologia e linguagem. A palavra, sob esse aspecto, está sempre carregada de valores, e são precisamente esses valores nos quais ela é sustentada que permitem entender sua 
função ideológica. Salienta-se assim que é a maneira como a palavra se inscreve em uma ou outra ordem histórico-simbólica que vai dotá-la de valores, significando distintivamente em cada época, em cada espaço social, institucional, em cada meio de produção refletindo ou refratando determinadas realidades (cf. BAKHTIN, 2011).

Pode-se observar no enunciado a seguir, revelador da relação de alteridade dos signos "branco" e "negro", a valorização do branco em detrimento do negro: "Branco correndo é atleta, negro é ladrão" (Designer, Rio Grande do Sul, 27 anos). A palavra "correndo" também assume uma função de signo ideológico ao refletir o ato de correr e refratar sentidos em contraposição: ao se referir ao branco, assume o sentido de um ato de participação em corrida ("atleta") e, ao se referir ao negro, assume o sentido de um ato de apropriação de um bem alheio ("ladrão"). Esse enunciado carrega a construção de uma imagem positiva do branco em oposição a um estereótipo negativo que é construído do negro.

O poder das palavras na circulação dos discursos relativos a brancos e negros, ao avaliar positivamente o primeiro e negativamente o segundo, vai naturalizando avaliações cristalizadas, preconceituosas e estereotipadas. Nesse processo, a identidade constrói-se a partir de representações do "eu" e do "outro", um "nós" e "outros". O estereótipo se forma como uma representação compartilhada, participa da construção identitária do "eu" e de sua comunidade, do grupo em relação a "outro". Trata-se de um grupo que se define mais como "suas fronteiras simbólicas" - que o estereótipo ajuda a consolidar - apenas por características internas específicas (AMOSSY, 2017). Esse poder estruturante faz com que o estereótipo, através da linguagem e das representações que carrega, tenha uma força que age sobre as práticas sociais. Para ilustrar essa noção de representação compartilhada do estereótipo e de inferioridade, passemos a analisar um outro enunciado, parte da resposta de uma professora:
"Ser confundida - e maltratada - com empregada doméstica no meu prédio, e com babá do meu próprio filho por ele ser de pele e olhos claros. Considero discriminação não por ser de pele e olhos claros. Considero discriminação não por ser demérito as profissões mencionadas, mas por se acreditar que nós, mulheres negras, só podemos transitar em esferas da classe média em posições subalternas." (Professora, Salvador 36 anos)

Na manifestação da professora, percebemos que há uma rede dialógica que sustenta o signo "mulheres negras". O fato de ser "negra" por si só já remete a associações de funções de menor reconhecimento social, como "empregada doméstica", no prédio em que mora, e como "babá", pelo fato de ter um filho "de pele e olhos claros". Essas palavras, valoradas negativamente, na construção do enunciado remetem ao contexto maior em que o enunciado se insere. Como observa Bakhtin (2011), o discurso é constituído a partir de posições sociais e é sempre uma réplica ou um complemento a um outro discurso, um posicionamento com relação a outro discurso. As palavras isoladas só revestem uma apreciação social quando inseridas em uma esfera semântica, um discurso (BAKHTIN, 2011).

$\mathrm{Na}$ cadeia discursiva em foco, podemos perceber no enunciado da professora vozes que desqualificam o negro de modo geral e a mulher negra de modo particular. $\mathrm{O}$ enunciado dialoga com vozes que consideram como referência o branco como morador de prédio de classe média. Dialoga também com vozes que consideram como referência de mãe de criança branca mulher branca. Ou seja, há uma centralização na pessoa de cor branca em contrapartida a de cor preta. Essa valoração negativa, além de hierarquizar em classes sociais as pessoas a partir da cor da pele, revela uma discriminação do negro, que somente poderia "transitar em esferas de classe média em posições subalternas". Com aparência de apenas uma simples confusão ("ser confundida"), a pessoa é maltratada, para usar as palavras da professora. 
O enunciado em análise revela o poder das palavras racistas e o quão a discriminação racial está implícita no imaginário coletivo. Os negros são desvalorizados na sociedade, e às mulheres negras cabem apenas funções sem prestígio social. Essas constatações reiteram os estereótipos e preconceitos vinculados à intolerância aos homens negros e às mulheres negras.

Quanto às palavras destacadas em segundo plano (2), moreno, inferior e revolto (em referência ao cabelo), o signo "moreno" é utilizado em certos contextos na tentativa de atenuar o termo "negro". Esse é o caso de termos eufemizados, como "moreninho(a)" e outros usados para fazer referência à pessoa negra, como destacado no levantamento de palavras. Esses termos, frequentemente, ditos no diminutivo, como "escurinho" ou "moreninho", embora aparentemente "gentis", carregam um valor semântico muito negativo na visão dos entrevistados, como no enunciado: "Ahh... mas você é bonita e não é tão negra assim, você é morena." (Jornalista, Rio de Janeiro, 28 anos).

A valoração atribuída ao enunciado reflete e refrata como o branco vê a negra, um embate entre "ser bonita" e "não ser tão negra". Nesse confronto, podemos perceber o tom discriminatório que tem como referência de beleza a cor branca. Ao utilizar o intensificador "tão" em referência à "negra", na expressão "não é tão negra assim", revela uma avaliação voltada para uma desvalorização da cor da pele preta. Quanto menos preta a pele, mais chance de ser considerada bonita. Por isso, o signo "morena", em "você é morena", tem um valor eufemizado, que mostra o preconceito com o negro.

De acordo com Fiorin (2017), "o cuidado excessivo na busca de eufemismos para designar certos grupos sociais revela a existência de preconceitos arraigados na vida social." Esse é o caso do seguinte enunciado: “Nossa mas você não é negra, você até é Clarinha!" (Autônoma, São Paulo, 31 anos). Essa valoração, revelada na relação entre "não é negra" e "até é
Clarinha !", põe em circulação vozes preconceituosas, que, no embate entre "não ser negra" e "ser até Clarinha", procura negar a legitimidade do negro na sociedade. Nos dois enunciados, podemos perceber essa negação: "não é tão negra assim" e "você não é negra". Também nos dois enunciados, recorre-se ao eufemismo como modo de amenizar o que seria um defeito do outro. Por isso o uso dos signos discriminatórios "morena" e "Clarinha", este último qualificado pelo operador "até", que indica o argumento mais forte.

Enunciados como esses colocam em cena o que Bourdieu (2008) considera como estratégias de eufemização (no sentido freudiano) de empregar uma característica fundamental da linguagem, a saber, priorizar a forma sobre o conteúdo, para ocultar elementos reprimidos. Essas tentativas de amenizar um discurso são vãs, visto que não há neutralidade na linguagem (cf. BAKTHIN, 2017) e, nos enunciados analisados, mostram o poder das palavras que, revestidas com tom "atenuador", revelam o preconceito nas relações sociais.

No que diz respeito às palavras (e suas variações) relativas ao terceiro plano (3), como preguiçoso, marginal, pobre, violento, mulato, sujo e excluído, bem como as que fazem alusão a cabelo crespo - ruim, duro e pixaim -, podemos perceber, nos enunciados proferidos pelos afrodescendentes, valores de inferioridade e exclusão que são atribuídos aos negros. Muitos enunciados fazem emergir a circulação de estereótipos, tão presentes no discurso cotidiano dos brasileiros.

A negritude brasileira tem dado passos no avanço para uma mudança de paradigmas na sociedade. Ainda que isso se faça lentamente, toda a evolução é significativa. Segundo Hall (1997), reverter o estereótipo não significa destruí-lo. Uma das formas possíveis de refutar estereótipos é a de valorá-lo positivamente em ocorrências em que teria o valor negativo. Esse é o caso do termo "negro" que tem hoje um valor positivo para muitos intelectuais da negritude. É importante observar, no entanto, as relações 
entre os interlocutores (quem diz? para quem? com que intuito? em que situação?) para então verificar o valor da palavra e/ou enunciado assumido no discurso.

No enunciado "Essa cor suja" (Estudante, 21 anos, Cachoeira), em que a palavra "suja" refere-se à cor da pele, é possível perceber o preconceito à cor preta da estudante ao considerá-la "suja", o que pretende legitimar a cor da pele branca como "limpa". Nesse jogo de poder, em que se desqualifica o negro, percebe-se uma tentativa de autovalorização em detrimento do outro.

Na mesma perspectiva, a palavra "pixaim", associada a outras no discurso, também é resultado de julgamento, o que pode ser observado no enunciado que segue, quando a entrevistada, aos 13 anos, recusou emprestar seu caderno para que os colegas da escola copiassem o conteúdo que haviam perdido: "Sua preta fedida, cabelo de pixaim, só pode ter saído da macumba... Odeio você, preta dos infernos". (Jornalista, São Paulo, 29 anos). Associar à estudante negra os signos "preta fedida", "cabelo de pixaim", "macumba" e "preta dos infernos" revela o alto grau de intolerância, discriminação e preconceito ao outro e ao seu grupo social. Voltando-se para a questão do poder da palavra, é possível observar a potencialização das tensões vividas pela adolescente na escola com colegas racistas, que pode ser resumida no segmento "odeio você, preta dos infernos".

Quanto aos adjetivos que se referem ao cabelo crespo (duro, ruim, sujo, armado, difícil, péssimo, feio, pixaim etc.), é possível observar que a valoração à materialidade do cabelo está de acordo com o que as normas estéticas dominantes consideram como negativas (cf. CHARAUDEAU, 2017) ${ }^{10}$. No enunciado "Falaram que meu cabelo era ruim, cabelo de preto. Já me chamaram de macaca. Na internet, quando falei algo que não concordaram falaram 'tinha que ser preta'” (Estudante, São Paulo, 18 anos),

${ }^{10}$ Conversas com Patrick Charaudeau em 22 março de 2017. a ênfase ao cabelo de preto ser "ruim" desqualifica a estudante em relação à referência estética do cabelo de branco, que seria "bom". Também se associa às discriminações o enunciado "tinha que ser preto", que reforça a discriminação racial no país.

No enunciado da estudante ainda se observa o signo ideológico "macaca(o)", bastante difundido entre os insultos aos negros, que reiteram os conflitos e as exclusões sociais. Essa designação é representativa do retrocesso pelo qual passa a sociedade brasileira ao tolerar a intolerância ao negro:

"A primeira discriminação, foi no bairro onde moro e na escola através das crianças com quem cresci, que [foi] onde eu pude entender o contexto que separa as pessoas de pele escura das outras, me chamavam de macaco, e faziam piadas com a minha cor. Assim mexendo com a minha autoestima me isolando num canto." (Fotógrafo, São Paulo, 23 anos)

Pode-se observar que a discriminação racial está entranhada na sociedade e revela-se desde a tenra idade em diferentes contextos, como no bairro e na escola, e marca a relação de alteridade discriminante e potencialmente conflitiva entre brancos e negros. Marca também como os insultos, por meio de palavras e suas valorações, potencializam as tensões vividas no cotidiano e interferem na autoestima das pessoas discriminadas.

O signo "macaco" também aparece em relatos sobre abordagens policiais, sobretudo com jovens negros habitantes das periferias, ligando-os à violência e à pobreza. Também se observa a relação com funções, trabalhos ou posições pouco valorizadas na sociedade a que os negros são associados: "[Fui] chamado de macaco no colégio, ser revistado pela polícia, ser confundido com segurança durante um show musical" (Jornalista, Fortaleza, 54 anos). 
Nesse campo semântico, ainda pode aparecer a palavra "corvo". São denominações de animais que, quando atribuídas a pessoas, se tornam negativas e insultantes. No caso do emprego do termo "macaco", isso reenvia as pessoas negras a um estado de espécies primitivas, ou sub-homens. Este inclusive é o insulto que aparece com bastante frequência, tanto na vida cotidiana, mas também no esporte, sobretudo no futebol, segundo dados de um estudo desenvolvido pelo Observatório ${ }^{11}$ do Racismo no Futebol, em Porto Alegre. Quanto ao uso da palavra "corvo", cria-se uma imagem do negro ligada a um pássaro da miséria, um animal que respira a morte.

As narrativas acima evidenciam, sobretudo, a influência sorrateira na linguagem das teorias racistas, segundo as quais o negro não seria um verdadeiro ser humano, mas "algo" entre este e o animal. Esta animalização do negro traduz a resistência de muitos brancos de considerar o negro como seu igual.

A partir do ângulo em que foram analisados os relatos, percebe-se que a grande maioria das opiniões emitidas pelos indivíduos é social e não se dirige somente a um interlocutor direto. São diferentes projeções, entre as quais a relação a outros enunciados passados ou futuros. Nossa análise salienta, assim, os conflitos que os conteúdos explícitos provocam no dia-a-dia dos afrodescendentes. Além destes, há muito outros subtendidos, que fazem parte de jogos argumentativos estratégicos e, mediante recursos de polidez, permitem expor ideias "não confessáveis" ou não aceitas socialmente (pelo menos de forma oficial), embora a grande maioria dos relatos evoque discursos que nunca deveriam ser tolerados em lugar algum.

${ }^{11}$ Entrevista com Marcelo Carvalho: diretor do Observatório do Racismo no Futebol, dados de 2016
<http://observatorioracialfutebol.com.br/o-brasil-e-um-pais-racista-mesmo-nao-se-assumindo$<$ http://observ
como-tal/>.

\section{Considerações finais}

Ainda que o avanço do debate no espaço público seja de notável importância e tenha quase extinto o errôneo conceito de hierarquia das raças, a cor da pele continua sendo um dos maiores critérios discriminatórios pelo mundo afora, em particular no Brasil. O que foi escrito até agora sobre raças e seu falso conceito só faz sentido em uma sociedade racista, visto que em um país ou cultura onde não fossem toleradas tais discriminações esses enunciados não teriam o menor sentido.

A sociedade brasileira, através do mito da "democracia racial" foi de tal modo estruturada pela história e pela política que, mesmo em condições modernas, ainda que de maneira eufemizada e disfarçada, mantém as regalias da época da escravidão. A polêmica das cotas que favorecem os negros no ingresso à universidade exemplifica esse conflito social no Brasil de hoje. Esta medida mínima de reparação por tantos anos de exclusão do(a)(s) negro(a)(s) do ensino superior desencadeia controvérsias, tendo em vista a resistência de uma fração importante da sociedade a qualquer ascensão social dos afrodescendentes, a qualquer figuração de destaque destes no espaço público.

A articulação do pensamento de dois teóricos da linguagem, Bakhtin e Bourdieu, que convergem quando afirmam a importância do sujeito na linguagem, permite entender mais claramente o funcionamento da estrutura hierárquica da sociedade brasileira e o papel da linguagem na manutenção das formas de discriminação contra os afrodescendentes. Como sublinharam esses dois teóricos, a língua sofre as influências do contexto social, da luta de classes e, naturalmente, da ideologia dominante, condicionados pela ordem social, pela história e pelos sujeitos como produtores de sentidos. Ao mesmo tempo, essa linguagem assim conformada servirá de instrumento para a manutenção das estruturas que a engendraram. 
Além disso, partindo do princípio de que o racismo no Brasil é estrutural e institucional, a pesquisadora Lia Schumann (2012) propõe o conceito de "letramento racial", que significaria uma tomada de consciência, por parte da sociedade em grande escala, de que ela é alicerçada sob uma forte base eurocêntrica e direcionada pelos privilégios simbólicos ou não de uma minoria branca. Salientando que o racismo se solidifica através da linguagem, o "letramento racial" contribuiria com a compreensão de que o racismo é uma questão atual, com a aquisição de um vocabulário racial e com o reconhecimento das consequências do passado, o que permitiria a implementação de medidas de valorização das raízes africanas de uma maioria dominada, uma maioria que é ainda tratada como minoria.

Por trás da ilusão da democracia racial, nesse contexto, as crianças continuam a reproduzir as estruturas do racismo com toda a crueldade que aprendem com os adultos. As crianças negras são confrontadas a insultos e muito desrespeito.

Com essa questão racial que tanto fragmenta os brasileiros, finalizamos este texto citando uma entrevistada que mencionou não ser negra, mas deixou esse registro marcante: "Não sou negra, mas minha neta é, portanto meu coração é negro".

\section{Referências}

AMOSSY, Ruth. Apologia da polêmica. São Paulo: Contexto, 2017.

AMOSSY, Ruth; PIERROT, Anne H. Stéréotypes et clichés. Paris: Armand Colin, 2015.

BAKHTIN, Mikhail. Os gêneros do discurso. Organização, tradução, posfácio e notas de Paulo Bezerra. Notas da edição russa de Serguei Botcharov. Rio de Janeiro: Editora 34, 2016.

BAKHTIN, Mikhail. Palavra própria e palavra outra na sintaxe da enunciação. São Carlos: Pedro \& João Editores, 2011.
BAKHTIN, Mikhail. $O$ autor e a personagem na atividade estética. In: Estética da criação verbal. Tradução de Paulo Bezerra. 4. ed. São Paulo: Martins Fontes, 2003.

BAKHTIN, Mikhail. [VOLOCHINOV] (Círculo de Bakhtin). (1929). Marxismo e filosofia da linguagem: problemas fundamentais do método sociológico na ciência da linguagem Trad. Michel Lahud e Yara Vieira. São Paulo: Editora Hucitec, 2017. <http://hugoribeiro. com.br/biblioteca-digital/Bakhtin-Marxismo_filosofia_linguagem.pdf> $(2016,12$. ed.).

BORGES, Pedro; NETO, Solon. Como a linguagem reforça o racismo no Brasil? Agência temática Alma Preta, 2017. Disponível em: <https://almapreta.com/editorias/ realidade/como-a-linguagem-reforca-o-racismo-no-brasil>. Acesso em 20 fev. 2018.

BOURDIEU, Pierre. A economia das trocas linguísticas. São Paulo: Edusp, 2008.

BOURDIEU, Pierre. Langage et pouvoir symbolique. Paris: Seuil, 2002.

BOURDIEU, Pierre. Ce que parler veut dire. Paris: Fayard, 1982. https://edc.revues. org/3326

CHARAUDEAU, Patrick. Conversas com o Professor Patrick Charaudeau. 22 março de 2017.

CHARAUDEAU, Patrick. A conquista da opinião pública: como o discurso manipula as escolhas políticas. Trad. Angela M. S. Corrêa. São Paulo: Contexto, 2016.

DAMATTA Roberto. Carnavais, malandros e heróis: para uma sociologia do dilema brasileiro. Rio de Janeiro: Rocco, 1997

DAMATTA Roberto. Relativizando. Uma teoria da antropologia social. Rio de Janeiro: Rocco, 1987.

FAUSTO, Boris. História do Brasil. São Paulo: Editora da USP, 2007.

FIORIN José Luiz. Argumentação. São Paulo: Contexto, 2017.

FOUCAULT, Michel. Microfísica do poder. Rio de Janeiro: Paz e terra, Record, 2014.

FOUCAULT, Michel. Genealogia del racismo. Madrid: Ediciones de la Piqueta, 1992.

GIRARDI JR., Liráucio. Pierre Bourdieu: mercados linguísticos e poder simbólico. Revista Famecos, PUCRS, v. 24, n. 3, 2017.

GOFFMANN, Erwing. (1963). Estigma - Notas sobre a manipulação da identidade deteriorada. Rio de Janeiro: LTC, 1981

GUERREIRO Ramos, Alberto. Introdução crítica à sociologia brasileira. Rio de Janeiro: Editora da UFRJ, 1995 
HALL, Stuart. Race, articulation and societies structured in dominance. Paris: UNESCO, 2013.

HALL, Stuart. Stereotyping as a Signifying Practice from Representation: Cultural Representations and Signifying Practices. London, Thousand Oaks: Sage Publications, Inc., 1997.

LANDES, Ruth. The City of Women. Albuquerque: University of New Mexico Press, 1994. LÉVI-STRAUSS, Claude. Raça e História. In: Antropologia Estrutural II. Rio de Janeiro: Tempo Brasileiro. 1976. Cap. XVIII, p. 328-366.

LOPES, Fernando. Experiências desiguais ao nascer, viver, adoecer e morrer: tópicos em saúde da população negra no Brasil. Brasília: FUNASA, 2005.

MAINGUEnEAU, Dominique. Discurso e análise do discurso. Trad. Sírio Possenti. São Paulo: Parábola Editorial, 2015.

MOURA, Clóvis. Os dilemas da negritude. In: Brasil: as raízes do protesto negro. São Paulo: Global Ed., 1983.

MUNANGA, Kabengele. Algumas considerações sobre raça, ação afirmativa e identidade negra no Brasil. Revista USP, São Paulo, 2005-2006.

MUNANGA, Kabengele. Negritude afro-brasileira: perspectivas e dificuldades. Revista de Antropologia, USP, p. 109-117, 1990.

ORLANDI, Eni. Silêncios: presença e ausência. Com Ciência - Revista de Jornalismo Científico, 2008.

ORLANDI, Eni. Interpretação: autoria, leitura e efeitos do trabalho simbólico. Petrópolis: Vozes, 1996.

PALMARES, Fundação Cultural. Quilombos ainda existem no Brasil. Disponível em: <http://www.palmares.gov.br/archives/3041>. Acesso em: 21 fev. 2018.

PEREIRA, Cícero; TORRES, Ana Raquel Rosas; ALMEIDA, Saulo Teles. Um estudo do preconceito na perspectiva das representações sociais: análise da influência de um discurso justificador da discriminação no preconceito racial. Psicologia: Reflexão e Crítica, v. 16, n. 1, p. 95-107, 2003.

PIRES, Vera. Dialogismo e alteridade ou a teoria da enunciação em Bakhtin. Organon, UFRGS, v. 16, n. 32-33, 2002

RIBEIRO, Djamila. O que é lugar de fala? Belo Horizonte: Ed. Letramento, Justificando, 2017.
RIBEIRO, Goulart Ana Paula; SACRAMENTO Igor (Org.). Mikhail Bakhtin: linguagem, cultura e mídia. São Carlos: Pedro e João Editores, 2010.

SARTRE, Jean Paul. Critique de la raison dialectique. Paris: Gallimard, 1960.

SCHUCMANN, Lia. Sim, nós somos racistas. Estudo psicossocial da branquitude paulista. Psicologia \& Sociedade, v. 26, n. 1, p. 83-94, 2014.

SCHUCMANN, Lia. Entre o encardido, o branco e o branquíssimo: raça e poder na hierarquia da branquitude paulistana. Tese (Doutorado em Psicologia Social) Universidade de São Paulo, São Paulo, 2012.

SOUZA, Jessé. A ralé brasileira: quem é e como vive. Belo Horizonte: Ed. da UFMG, 2016 SOUZA, Neusa. Torna-se negro ou As vicissitudes da identidade do negro brasileiro em ascensão social. Rio de Janeiro: Ed. Graal, 1983.

SOVIK, Liv. Aqui ninguém é branco. Rio de Janeiro: Aeroplano, 2009.

TAGUIEFF, Pierre-André. Dictionnaire historique et critique du racisme. Paris: PUF, 2013. TELLES, Edward Eric. Racismo à brasileira: uma nova perspectiva sociológica. Rio de Janeiro: Relume Dumará, 2003.

Recebido em $07 / 02 / 2018$ Aceito em 02/05/2018. 